\title{
Contextualización educativa: ética, política y transdisciplinariedad
}

\author{
Juan Miguel Batalloso* \\ Maria Cándida Moraes ${ }^{* *}$
}

\section{Resumen}

Contextualizar educativamente significa analizar críticamente y tomar en consideración las condiciones materiales, personales. sociales y profesionales de existencia en las que viven educadores y educandos, con el fin de que las organizaciones e instituciones formativas y educativas ayuden y contribuyan a remover o eliminar todos aquellos obstáculos y dificultades que se oponen o frenan el desarrollo integral de las personas en la perspectiva de su más plena humanización.

El proceso de contextualización educativa no debe consistir exclusivamente en un procedimiento de investigación social para generar informes que acaban en los cajones de los despachos de los funcionarios de la administración educativa, como tampoco en un proceso de comunicación de arriba hacia abajo en el que los funcionarios especializados determinan y dictaminan lo que debe o no hacerse para mejorar las prácticas educativas. Es más bien un proceso horizontal de diálogo permanente al estilo de los "Círculos de Cultura" que Paulo Freire ideó y puso en práctica para alfabetizar a los campesinos (FREIRE, P.; 1976) que consiste básicamente en dar, o más bien conquistar y hacer posible el uso de la palabra a los que nunca la tuvieron y fueron siempre los sujetos sufrientes de un sistema de dominación. Un proceso en el que educadores, educandos y ciudadanía de un contexto concreto, se implican, participan, acuerdan y gestionan todas las medidas y acciones necesarias para liberarse de todos los obstáculos que impiden su educación, tanto como desarrollo personal, profesional

* Doutor em Educação - Universidade de Sevilha - Espanha; Pesquisador do Instituto Paulo Freire da Espanha. batalloso@outlook.es

** Doutora em Educação pela PUC/SP. Pesquisadora do IIPC - Instituto Internacional do Pensamento Complexo - Argentina, professora convidada da Universidade de Barcelona - Espanha. mariacandidam4@gmail.com 
y humano pleno, así como también de desarrollo comunitario y particularmente de mejoramiento y aumento de la calidad de los servicios que ofrecen las instituciones educativas. $\mathrm{Y}$ esto obviamente exige considerar

y hacer visibles en todas las prácticas educativas las dimensiones éticas y políticas de la Educación desde una perspectiva transdisciplinar.

Palabras clave: Contextualización educativa; praxis educativa; ética y política educativa; complejidad y educación; educación transdisciplinar.

\section{Educational contextualization: ethics, politics and transdisciplinarity}

\section{Summary}

Contextualizing, in education, means critically analyzing and taking into account material, personal conditions, social and professional of existence in which educators and students live, so that educational organizations and institutions help and contribute to remove or eliminate all those obstacles and difficulties that oppose or hinder the integral development of people in the perspective of their fullest humanization.

The process of educational contextualization should not consist exclusively of a social investigation procedure to generate reports that end up in the drawers of the desks of the employees of the educational administration, nor in a top-down communication process in which specialized employees determine what should or should not be done to improve educational practices._It is another horizontal process of permanent dialogue in the style of the "Circles of Culture" that Paulo Freire idealized and put into practice to literacy the peasants and that basically consists of offering, or rather, to conquer and enable the use of the word to those who never had it and have always been subjects suffering from a system of domination._A process in which educators, students and citizenship from a concrete context are involved, participated in, agree and managed all the measures and actions necessary to release themselves from all obstacles that hinder their education, both with regard to personal, professional and human development, as well as in community development and, particularly, in improving and increasing the quality of services offered by educational institutions. And this obviously requires considering and making visible in all educational practices the ethical and political dimensions of Education, from a transdisciplinary perspective.

Keywords: Educational contextualization; educational praxis; ethics and educational policy; complexity and education; transdisciplinary education 


\section{Contextualização educativa: ética, política e trans- disciplinaridade}

\section{Resumo}

Contextualizar, em educação, significa analisar criticamente levando em consideração as condições materiais, pessoais, sociais e profissionais existentes nas quais vivem educadores e educandos, visando que as organizações e instituições formativas e educativas contribuam para remover ou eliminar todos aqueles obstáculos e dificuldades que se opõem ou freiam o desenvolvimento integral das pessoas, na perspectiva de sua mais plena humanização.

O processo de contextualização educativa não deve consistir exclusivamente em um procedimento de investigação social para gerar informes que acabam nas gavetas das escrivaninhas dos funcionários da administração educacional, como tampouco em um processo de comunicação de cima para baixo no qual os funcionários especializados determinam o que deve ou não ser feito para melhorar as práticas educativas. É mais um processo horizontal de diálogo permanente no estilo dos "Círculos de Cultura" que Paulo Freire idealizou e colocou em prática para alfabetizar os camponeses e que consiste, basicamente, em oferecer, ou melhor, em conquistar e possibilitar o uso da palavra aos que nunca a tiveram e sempre foram sujeitos sofredores de uma sistema de dominação. Um processo no qual educadores, educandos e cidadania de um contexto concreto se implicam, participam , concordam e gestionam todas as medidas e ações necessárias para se liberarem de todos os obstáculos que impedem sua educação, tanto no que se refere ao desenvolvimento pessoal, profissional e humano, como também no desenvolvimento comunitário e, particularmente, na melhoria e no aumento da qualidade dos serviços oferecidos pelas instituições educativas. E isto obviamente exige considerar e tornar visível em todas as práticas educativas as dimensões éticas e políticas da Educação, desde uma perspectiva transdisciplinar.

Palavras-chave: Contextualização educativa; práxis educativa; ética e política educativa; complexidade e educação; educação transdisciplinar.

«...Si se teoriza sobre la educación, es para servir a la práctica, al ejercicio profesional del educar. No se concibe una teoría educativa que no pueda incidir positivamente sobre la práctica; no se concibe una teoría que no sea pragmática, que no sea útil, que con ella no se pueda mejorar y perfeccionar el mundo práctico de la educación. De hecho, una Teoría de la Educación que no sirviese para mejorar la educación sería una teoría absurda. 
En educación, si se teoriza, es para mejorar la propia educación. Por tanto, es imposible confundir o querer igualar la Filosofía de la Educación con la Teoría de la Educación, ya que aquella no busca aplicabilidad alguna, al menos de forma directa o inmediata...»

Antonio J. Colom

\section{La Teoría de la Educación en su doble dimensionalidad:}

Como teoría acerca de la realidad y como teoría acerca del

saber educativo Coímbra: Revista Portuguesa de Pedagogía. 2006.

Contextualizar educativamente no es analizar las condiciones materiales, personales y profesionales de existencia en las que viven educadores y educandos para que estos se adapten y obedezcan estrictamente a las normas y estructuras burocráticas de las organizaciones e instituciones educativas. Es precisamente lo contrario, es decir, analizar y tener en cuenta esas condiciones, con el fin de que las organizaciones e instituciones formativas y educativas prefiguren en su seno las finalidades más originales y auténticas de Educación ayudando y contribuyendo así a eliminar todos aquellos obstáculos y dificultades que se oponen o frenan el desarrollo pleno e integral de las personas. No son pues los agentes educativos los que tienen que obedecer y adaptarse fielmente a lo que establecen y preceptúan estructuras burocráticas y administrativas de la Educación, por lo general alejadas de la vida cotidiana de las aulas y demasiado apegadas al profesionalismo especializado de funcionarios que obedecen a directrices políticas e ideológicas coyunturales.

El proceso de contextualización educativa, tal y como lo entendemos aquí, ni es un procedimiento de investigación social para generar informes que acaban en los cajones de los despachos de los funcionarios de la administración educativa, como tampoco un proceso de comunicación de arriba hacia abajo en el que los funcionarios especializados determinan y dictaminan lo que debe o no hacerse para mejorar las prácticas educativas. Es más bien un proceso horizontal de diálogo permanente al estilo de los "Círculos de Cultura" que Paulo Freire ideó y puso en práctica para alfabetizar a los campesinos (FREIRE, 1976) que consiste básicamente en 
dar, o más bien conquistar y hacer posible el uso de la palabra a los que nunca la tuvieron y fueron siempre los sujetos sufrientes de un sistema de dominación. Un proceso en el que educadores, educandos y ciudadanía de un contexto concreto, se implican, participan, acuerdan y gestionan todas las medidas y acciones necesarias para liberarse de todos los obstáculos que impiden su educación, tanto como desarrollo personal, profesional y humano pleno, así como también de desarrollo comunitario y particularmente de mejoramiento y aumento de la calidad de los servicios que ofrecen las instituciones educativas.

Contextualizar educativamente significa entonces, crear permanentemente un foro de praxis educativa, es decir, de reflexión acción y reflexión críticas sobre aquellos aspectos que pueden y deben removerse y mejorarse para ayudar más eficientemente a los educandos. Un foro, que, a modo de una asamblea permanente o consejo social y educativo de cada institución, implicase y responsabilizase no solo a los profesionales de la docencia y a sus alumnos, sino a toda la ciudadanía y especialmente a aquellos agentes sociales que, de uno u otro modo, influyen, condicionan y orientan las finalidades y funcionamiento de las instituciones. Esto obviamente exigiría que los procedimientos burocráticos legalmente establecidos partiesen y se basasen en los principios de flexibilidad, autonomía, participación, coordinación y valores democráticos de responsabilidad social de todas las instituciones escolares. Y así, nuestras Escuelas iniciarían un proceso abierto y permanente de autoformación, cualificación y desempeño en la perspectiva de hacerse plenamente públicas, democráticas y de calidad, algo, por cierto, que no puede hacerse a base de voluntarismo, heroísmo, vanguardismo o de prácticas asistenciales y paternalistas, sino de compromiso del Estado con la financiación pública de la Educación, ya que esta es un Derecho Humano Universal y no una mercancía más que puede venderse o comprarse en un supermercado. Una financiación desde luego que debe priorizar, antes que nada, la mejora sustancial de las condiciones laborales y salariales del profesorado que trabaja en los 
niveles de enseñanza obligatoria y que presta sus servicios en las zonas sociales más vulnerables y discriminadas.

Una propuesta así, entendemos que únicamente puede llevarse a efecto, si se conocen y se asumen unos principios éticos, políticos y transdisciplinares que a continuación trataremos brevemente de describir.

\section{La dimensión ética}

Coincidimos con el profesor A. J. Colom cuando afirma que la Teoría de la Educación posee una epistemología débil, en el sentido de que tiene una estructura abierta y su identidad es esencialmente de carácter narrativo porque no puede agarrarse ni encerrarse en identidades, ontologías, filosofías, doctrinas o principios morales externos. Y esto es así también porque los saberes educativos son necesariamente saberes críticos, inestables, en constante y permanente construcción, deconstrucción y reconstrucción.

Este carácter crítico de la Teoría de la Educación lógicamente está asociado a su finalidad práctica, porque educar es ante todo y sobre todo un hacer en, con, para los sujetos que se educan, por lo que exige continuas acciones y reflexiones de recreación, reconstrucción y reorientación. Un carácter, por cierto, que prefiguró coherentemente en toda su obra, su pensamiento y su acción el insigne y universal pedagogo y educador Paulo Freire, quien concebía la Educación como una praxis, es decir, como un proceso permanente de acción, reflexión y acción que fundado e informado por la Ética de los Derechos Humanos Universales, se dirigía a transformar a las personas al mismo tiempo que estas se comprometían en la transformación del mundo desde el contexto concreto en que esas personas viven.

Esta es la razón por la que creemos que, si la Teoría Educación es un ámbito de conocimiento abierto, plural y de carácter eminentemente pluridisciplinar, interdisciplinar y transdisciplinar, que aspira a ofrecer orientaciones y principios para mejorar las prácticas educativas, es decir, para desarrollar de la forma más coherente y 
eficiente posible acciones que incrementen y sustenten la vida en todas sus dimensiones, no puede desentenderse de la Ética. De lo que sí debe a nuestro juicio desentenderse es de las éticas particularistas, fragmentarias, doctrinarias, dogmáticas y especializadas que intentan dar legitimidad a conductas individuales y sociales que niegan la vida. Y esto en otras palabras significa que no basta con los criterios de racionalidad científica y técnica, sino que hace falta un nuevo tipo de racionalidad que dé fundamento a aquellas prácticas educativas que generan, producen y sostienen la vida en todas las dimensiones planetarias y humanas.

Como dice Adela Cortina, los actos humanos en sí, no son ni buenos ni malos, porque lo que califica la bondad o maldad de un acto es su coherencia, acuerdo o subordinación a normas que se consideran como buenas o conformes a valores por los que previamente hemos optado. Sin embargo nuestros actos, dada la naturaleza de nuestra existencia como seres abocados a elegir, no podrán situarse nunca más allá de los límites del bien y del mal, no podrán salirse fuera del marco de lo ético-moral ${ }^{1}$ porque siempre llevarán dentro de ellos los criterios y las razones por los que se realizan: nuestra conducta podrá estar referida a unas razones o a otras, a unos sistemas de creencias morales o a otros, pero nunca podrán ser axiológicamente neutrales o moralmente vacías (CORTINA, 1994, p.102). En otros términos: es imposible, además de absurdo, situar los hechos educativos y los conocimientos pedagógicos más allá o al margen de la Ética.

Hemos optado por utilizar los términos "ética" y "moral" indistintamente de forma sinónima, si bien dichos vocablos no significan conceptualmente lo mismo, ya que lo moral, hace referencia a normas y prácticas de conducta y complementariamente lo ético supone una reflexión sobre el hecho moral, que intenta buscar criterios, razones y fundamentos, tanto de las normas, como de la conducta. No puede concebirse una educación ética sin una educación moral y tampoco una educación moral sin una educación ética, esta es la razón por la que educativamente hablando preferimos utilizar los dos términos indistintamente, entendiendo que ambos son complementarios e indisolubles desde un punto de vista educativo y pedagógico. 
La Ética surge de la necesidad de dar buenas razones a nuestros actos y como consecuencia del problema de la responsabilidad derivada de nuestras decisiones. La tarea entonces consiste en encontrar las razones más adecuadas y justificadas para que nuestros actos puedan ser considerados como buenos. Por ello y dependiendo de cuáles sean las razones o criterios que adoptemos, así se realizarán los diferentes sistemas éticos que conocemos, sistemas que han proporcionado siempre el substrato y el fundamento de cualquier teleología o antropología educativa. Corresponde pues a la Teoría de la Educación, no solo revisar críticamente los sistemas éticos que han dado y siguen dando fundamento a las prácticas educativas y/o a los procesos de enseñanza-aprendizaje y de orientación-desarrollo, sino también construir un nuevo tipo de racionalidad ética coherente con el resto de las fuentes de racionalidad. Es responsabilidad de la Teoría de la Educación, fundamentar, hacer posible y visible que las prácticas educativas estén orientadas por la Ética, dado que ningún conocimiento puede estar más allá del bien o del mal, o ser moralmente vacío.

Por otra parte, la grave y profunda crisis civilizatoria en la que nos encontramos, es sin duda debida, entre otros muchos factores, a la expresión de una profunda crisis ética consistente en el debilitamiento de la responsabilidad y la disminución de la solidaridad. Como señala Bauman, las sociedades y las relaciones se han hecho líquidas y con ello también las instituciones de acogida (familia, escuela, universidad, ciudad, barrio, partidos, sindicatos...) así como los dispositivos productores de sentido de etapas anteriores (educación, religión, ética, arte, sentimientos...) por ello vivimos en un estado de inseguridad, incertidumbre y desorientación de enorme impacto para la Educación y sus instituciones (BAUMAN, 2007). De una u otra manera se han ido deshaciendo los vínculos del bucle individuo-especie-sociedad (MORIN, 2006, p. 30), en consecuencia, es una responsabilidad también de la Teoría de la Educación procurar reestablecer esos vínculos, regenerar y fortalecer este bucle, tarea que no podemos afrontar ignorando los valores éticos 
de responsabilidad y solidaridad. Y esto obviamente tiene unas importantísimas consecuencias para la Educación, tanto en el plano de sus finalidades y de sus principios ontológicos, epistemológicos y metodológicos, como en el plano de la práctica concreta y de la responsabilidad social de educadores e instituciones educativas.

La Educación ya no puede consistir en acumular conocimientos que nada dicen sobre la realidad que viven alumnos y profesores; ni tampoco puede desarrollarse con métodos contradictorios a los fines y valores perseguidos. No podemos seguir enseñando la democracia mediante métodos autoritarios, como tampoco podemos enseñar la dignidad, la justicia o la fraternidad con procedimientos indignos, injustos e individualistas. Y si los valores esenciales que sostienen la Educación son la solidaridad y la responsabilidad, el problema ya no puede resolverse mediante paquetes curriculares especializados y descontextualizados sometidos a tiempos limitados por criterios completamente ajenos a las necesidades humanas. Ni la solidaridad, ni la responsabilidad pueden ya enseñarse mediante lecciones magistrales, lecturas de textos, actividades de papel-lápiz y mucho menos por métodos competitivos en los que se promueve la rivalidad y el individualismo.

La primera tarea por tanto de un proceso educativo fundado en la responsabilidad y en la solidaridad y de toda contextualización educativa, tendrá que consistir en el descubrimiento y la investigación analítica de todos aquellos factores y contradicciones que inciden o causan la deshumanización de educadores y educandos, con lo cual la dimensión epistemológica y la dimensión política de la contextualización educativa se conectan. Unos factores que habrá que buscar en el ambiente y la situación real concreta en la que existen, conviven y se desenvuelven las personas y los agentes educativos concretos, para seguidamente continuar con un análisis reflexivo más pormenorizado, que dé cuenta del grado de importancia de dichos factores deshumanizadores. Y todo ello con el fin de devolver ese análisis a la propia comunidad, para que sea ella y sólo ella la que adopte aquellas medidas más adecuadas para su humanización. 
Pero, además, se trata también de liberarse de cualquier forma de paternalismo, dependencia, dirigismo, burocratismo, dogmatismo o fatalismo. Un nuevo tipo de racionalidad ética que de sentido a la Teoría y a la Práctica de la Educación, sea cual sea su dimensión, exige al mismo tiempo, además de centrarse en la promoción y el desarrollo de la responsabilidad y la solidaridad, poner el foco en la dignidad y autonomía de los seres humanos y en el valor absoluto de la vida porque: «Ser digno es exigir el reconocimiento como sujetos, reencontrarse consigo mismo, confiar en nuestras propias capacidades y potencialidades de vivir y luchar. La dignidad es un valor fundamental de una ética de la autonomía y de la liberación, sobre todo en un momento bistórico donde la victimización y la negación de la vida trastocan todos los valores...» (REBELLATO 2000, p. 299).

Llegados a este punto y si la Educación es un proceso permanente de transformación personal y social, ligado a condiciones materiales sociohistóricas concretas, a concepciones filosóficas y propuestas culturales, así como también a experiencias de vida personal insertas en el bucle individuo-especie-sociedad, es obvio que su íntima conexión y vinculación con la Ética es muy profunda y al mismo tiempo muy ramificada o complejamente enredada. Ya sean los saberes pedagógicos, que son sobre todo saberes orientados a las prácticas educativas, o ya sea la conducta profesional concreta de cualquier educador, o cualquier forma de proyecto, programa o actividad curricular, o también cualquier estructura, organización o institución académica, estará irremisiblemente sustentada, alimentada o relacionada de algún modo con la Ética.

Así pues, creemos que para contextualizar la educación desde la dimensión epistemológica es indispensable adoptar e integrar la racionalidad ética que, se sustenta en la aspiración a conseguir el desarrollo de tres grandes objetivos

1. Hacer posible que las personas asuman personal y colectivamente la responsabilidad de desarrollarse como seres humanos, de mejorar y aumentar su nivel de humanización y esto implica necesariamente, como nos enseña 
Edgar Morin, de nuevos saberes educativos tales como enseñar y aprender la condición y comprensión humana, nuestra identidad terrenal, la ética del género humano así como la toma de conciencia de nuestras cegueras y errores. (MORIN, 1999).

2. Denunciar todo intento manipulador, autoritario, adoctrinador o adormecedor de nuestras conciencias. Impedir que se nos engañen, se nos mientan o se nos oculten las situaciones deshumanizadoras y las causas que las originan. Favorecer la expresión de alternativas, opciones, propuestas porque lo esencial no está en denunciar, sino en anunciar y posibilitar lo que todavía no es visible, pero es perfectamente probable a partir de nuestro esfuerzo y compromiso, o como decía Freire: «La cuestión está en cómo transformar las dificultades en posibilidades» (FREIRE, 1997, p. 63).

3. Aprender una estrategia metodológica del conocimiento que se haga y rehaga a sí misma en permanente diálogo de acción y reflexión con la realidad en la que intervengo y con los demás con los que convivo, coopero y me solidarizo. Una estrategia que sea coherente con la Ética de la justicia y la Ética del cuidado o con la dimensión política y compasiva del amor. Una estrategia metodológica que apunte a la transformación profunda de nuestras formas de sentir, pensar y hacer. Una estrategia dirigida a la transformación y el desarrollo integral de todas las dimensiones de nuestra conciencia, asumiendo creadoramente el hecho de que somos seres insertos permanentemente en la dinámica individuo-naturaleza-sociedad y que por tanto trabaja y se esfuerza en restaurar las separaciones producidas por las cegueras del conocimiento e intenta construir una nueva visión más acorde con las necesidades de la vida. 
En definitiva, de lo que se trata es de construir un nuevo tipo de racionalidad educativa capaz de desarrollar la fraternidad y el amor como valores y capacidades humanas de «...lucha práctica de la religación contra la separación, la dispersión, la muerte. Todo acto ético es un acto de religación, religación con el prójimo, religación con los suyos, religación con la comunidad, religación con la bumanidady, en última instancia, inserción en la religación cósmica (...) El amor es la religación antropológica suprema. El amor es la expresión superior de la ética...» (MORIN, 2006, p. 40-42).

\section{La dimensión política}

Los seres humanos somos seres de relación. De hecho, allí donde no haya relaciones de algún tipo, ya sea con el medio natural mediante la observación o la interacción, como con el medio social mediante los afectos, la comunicación y el diálogo, o con el propio mundo interior subjetivo del sí mismo de cada individuo, ni se puede construir conocimiento, ni puede existir aprendizaje, ni enseñanza, ni formación, ni educación. Los seres humanos somos seres de relaciones multidimensionales y nuestra existencia biológica, material, social, emocional y espiritual, como nos decía Martin Buber «... es el hombre con el hombre... un ser que busca a otro ser concreto, para comunicar con él en una esfera común a los dos, pero que sobrepasa el campo propio de cada uno... la esfera del "entre"...situada más allá de lo subjetivo, más acá de lo objetivo, en el "filo agudo" en el que el "yo" y el "tú" se encuentran...» (BUBER, 1993, p. 146). En definitiva, los seres humanos existimos y somos conscientes de nuestra existencia, no sólo porque poseamos capacidades de simbolización y comunicación, sino sobre todo porque gracias a ese ese espacio "entre" el yo y el tú, espacio de habla y de escucha, verificamos nuestra existencia. Un espacio que no es otro que el del diálogo entendido como fin que sustantiva y define al ser humano, pero también un diálogo considerado como medio de interacción de intercambio, de cooperación y sin el cual no es posible la existencia del hecho educativo.

Así pues, nuestra propia existencia como seres biológicos y sociales es una existencia de relación, comunicación, interacción e interdependencia. Sin embargo, en el cotidiano y al mismo tiempo 
milagroso acto de existir como humanos, cuya conciencia emerge también a partir de nuestras relaciones en el denominado «triângulo da vida» (D'AMBROSIO, 1998, apud MORAES, 2008, p. 40) siempre surge el fenómeno del poder. Un fenómeno que se expresa mediante la aceptación o prescripción de normas o procedimientos explícitos o implícitos de mando-obediencia o de resistencia-cooperación, ya sea en forma de control y apropiación de recursos o también como apropiación e imposición de discursos. Mas, ¿cómo definir el poder de una forma sencilla y visible?

Son numerosas las definiciones que se han dado a lo largo de la historia del término poder y está claro que tener poder es lo mismo que tener capacidad para hacer, decir o realizar algo, como así expresan todos los diccionarios de las diferentes lenguas. Sin embargo, lo que caracteriza la existencia y presencia del poder en las relaciones humanas es el hecho de la desigualdad. Así, siempre que constatemos la existencia de una circunstancia, acontecimiento, situación, o una relación en la que esté presente la desigualdad de posibilidades, ya sean estas económicas, culturales, sexuales, de etnia o políticas, podremos establecer con garantías que el poder está presente. Como dice el prestigioso periodista y economista español Joaquín Estefanía «...Poder es potestad, poderio, prepotencia, preponderancia, dominio, mando, privilegio, pero sobre todo superioridad; todo poder es una conspiración permanente contra el débil. Y cualquier ciudadano es débil respecto a otro o a alguna situación (...) Cada sociedad, cada institución social es una encrucijada de poderes que pugnan por imponerse unos a otros. Son vectores tirando en distinta dirección para ver cual es el más fuerte (...) Todo ejercicio de poder genera un ejercicio generalmente similar y opuesto (...) En la actualidad los poderes sociales son sancionados por el siguiente orden: hombre, blanco, heterosexual, acomodado, moderno y preferentemente norteamericano. El rasgo dominante de la sociedad a principios del siglo XXI es lo patriarcal, homofóbico, eurocentrista y capitalista. El resto de los grupos (mujeres, gays, negros y demás gente de color, excluidos, etc.) es reprimido...» (ESTEFANÍA, 2000, p. 21)

Lo queramos o no, el poder atraviesa todas las instituciones y relaciones humanas. En consecuencia, todas las relaciones y procesos educativos son de naturaleza política, naturaleza que no 
solamente procede del propio carácter de las relaciones, sino también del hecho de que todo proceso educativo es en realidad un amplio y continuo proceso de transformación personal y social, es decir, ligado al desarrollo de la vida humana y por tanto necesariamente comprometido con la mejora de las condiciones materiales de su existencia y con la mejora de la propia condición humana. Al mismo tiempo, sabemos también que ningún tipo de conocimiento se produce en el vacío y no está exento de influencias y condicionamientos históricos, sociales, culturales y económicos. No existe pues un conocimiento pedagógico o educativo puro, neutral e independiente de las condiciones históricas, sociales y políticas dadas y heredadas de antemano. Así como tampoco existe un curriculum o una metodología pedagógica o didáctica neutral o que no esté afectada o motivada por el paradigma civilizatorio dominante.

En consecuencia, todo fenómeno o proceso educativo, ya se exprese o manifieste de forma institucional, escolar, profesional o curricularmente, es intrínsecamente de naturaleza política tanto ontológica, teleológica, epistemológica como metodológica. Naturaleza que adquiere pleno vigor, cuando además la educación es un Derecho Humano Universal como así queda establecido en el artículo 26 de la Declaración Universal ${ }^{2}$.

Acerca de la naturaleza política de la educación, Paulo Freire nos recuerda que «...Sería extremadamente ingenuo pretender que las clases dominantes desarrollen un tipo de educación que permitiera a las clases sometidas, percibir críticamente las injusticias sociales. Eso demuestra que no existe una educación verdaderamente neutral (...) Al tratar de conocer científicamente la realidad en la que se origina nuestro tema no sólo deberíamos someter nuestros procedimientos epistemológicos a nuestra versión de "la verdad", sino también buscar la verdad basada en hechos. Sin embargo, durante esta investigación científica de la realidad no debemos asumir una actitud neutral. No podemos confundir nuestra preocupación por la verdad (característica de cualquier esfuerzo científico serio) con la así llamada neutralidad científica que de hecho no existe. Nuestra actitud comprometida, no neutra, hacia la realidad que procuramos conocer, debe en primer lugar generar conocimiento como proceso que implica acción y reflexión acerca del papel de hombre en el mundo. 
En este marco de referencia, lo que aquí nos interesa destacar, es que la naturaleza política de la educación y las relaciones de poder están presentes no solo en el planeta y en la sociedad, sino también en las instituciones, en las aulas y en las relaciones profesionales y personales que mantienen los agentes educativos, dado que el poder es un fenómeno extraordinariamente transversal. De este modo la identificación de las dimensiones políticas y pedagógicas de la contextualización educativa y a efectos puramente descriptivos o clarificadores, podemos hacerla enfocando nuestra mirada desde una triple perspectiva:

1. La perspectiva macropolítica, referida tanto a los impactos y efectos que el modo de producción económico y las organizaciones internacionales ejercen sobre las políticas educativas públicas nacionales, como al papel y la función que las instituciones educativas y formativas juegan en la sociedad de un determinado país.

2. La perspectiva mesopolítica o con relación a las estructuras organizativas de las instituciones escolares, académicas y profesionales, sus modos de gestión, sus culturas y prácticas profesionales y el tipo de relaciones que establecen los agentes educativos en el seno de las mismas.

3. La perspectiva micropolitica, o relativa a las relaciones personales, afectivas, emocionales que se dan en las aulas y en la propia organización escolar y que son la matriz en la que se construye y constituye el medioambiente y el clima psicosocial tanto de las aulas, como de la organización y la institución entera.

En virtud del carácter teleológico de la unidad que existe entre acción y reflexión (es decir, en la praxis) a través de la cual el hombre o la mujer que transforma la realidad es as u vez transformado, no es posible descartar esta actitud de compromiso, que, además, preserva su espíritu crítico y científico. No podemos permanecer éticamente indiferentes al destino que pueden imponer a nuestros hallazgos aquellos que tienen el poder de decisión, pero que sólo se entregan a la ciencia y a sus intereses $y$, subsiguientemente, dictan sus objetivos a la mayoría...» (FREIRE, 1990, p. 115 y 122) 
No es este el lugar, dadas las limitaciones de espacio, para analizar con detalle cada una de las características que configuran las perspectivas macropolítica, mesopolítica y micropolítica de la dimensión política de la contextualización educativa. No obstante baste con decir que cada una ellas está complejamente relacionadas entre si en una especie de bucle que se retroalimenta, influye y condiciona a los demás. En otras palabras: las características de las políticas dominantes del globo o planetarias, influyen y condicionan las políticas educativas nacionales y estas a su vez, mediante los procedimientos burocráticos legalmente establecidos, determinan lo que debe o no hacerse, así como el modo de hacerlo de las instituciones educativas y/o formativas. Y a su vez, las características organizativas de estas instituciones, las competencias profesionales y administrativas de los funcionarios docentes, así como los estilos y prácticas formativas que se han hecho rutinarias a través del tiempo y que no han sido cuestionadas en su legitimidad, vendrán necesariamente a influir y condicionar, el tipo de relaciones personales o micropolíticas que se establecen entre los agentes educativos.

Se trata pues de un amplio y complejo proceso de condicionamiento que funciona siguiendo líneas verticales de arriba hacia abajo, que van desde lo global a lo local, o desde lo institucional a las relaciones personales en las aulas y en el que los procesos de diálogo e interacción que permitiría una línea horizontal no aparecen por ningún sitio. $\mathrm{Y}$ esto es así, porque estos procesos están atravesados por una burocratización generalizada que establece y legaliza estructuras jerárquicas y relaciones de mando-obediencia, así como un entramado creciente de normativas y prescripciones que limitan, no solo la autonomía profesional del profesorado, sino que lo condenan a ser agentes funcionariales cuyo único papel es obedecer a lo establecido, consolidando así un sistema de "educación bancaria” (FREIRE, 1976) en la que el alumno es el último eslabón de una cadena de obediencia.

En este complejo escenario, hoy es más necesario que nunca, como nos señala Edgar Morin conjuntar esfuerzos profesiona- 
les y ciudadanos que nos permitan desburocratizar y democratizar las instituciones dotándolas de niveles de autonomía y creatividad coherentes con la complejidad de los procesos y competencias en las que están implicados: «...La democracia parlamentaria, por muy necesaria que sea, es insuficiente. Incluso está en vías de desvitalizarse allí donde el pensamiento político pierde vigor; hay un gran desinterés ciudadano y una considerable incapacidad para afrontar los grandes desafíos de la era planetaria...». En consecuencia, democratizar las políticas educativas públicas y las instituciones, desburocratizarlas, no puede consistir como hasta ahora ha venido siendo. No se trata crear órganos representativos hipertrofiados o esclerotizados en sus funciones, como tampoco de crear nuevas jerarquías y reglamentos. Es necesario recrear y reinventar la democracia, no exclusivamente como una forma de representación, sino como un espacio de participación y de protagonismo de la ciudadanía que a partir de unos valores y objetivos compartidos permita expresar e integrar la diversidad y complejidad de los problemas, de las interpretaciones y de las opiniones. Como dice Morin: «...Habría que concebir y proponer las diferentes modalidades de democracia participativa, sobre todo a escala local. Sería útil despertar a los ciudadanos y fomentar su interés, necesario para la regeneración del pensamiento político, que, a su vez, regeneraría las vocaciones militantes para hacerse cargo de los grandes problemas. También sería útil multiplicar el número de universidades populares, que ofrecerían a los ciudadanos una iniciación al pensamiento complejo con el que podrían abarcar los problemas fundamentales y globales impartiendo, por una parte, un conocimiento no mutilado y, por otra, una iniciación a las ciencias históricas, politicas, sociológicas, económicas y ecológicas. La democracia participativa debe inventarse a partir de diversas experiencias locales, como en el caso de Porto Alegre, donde se invitó a participar a los ciudadanos en el examen del presupuesto municipal, especialmente en lo referente a inversiones. Puede adoptar la forma de debates públicos a escala local o regional para que los ciudadanos valoren proyectos controvertidos (trazado de una autopista, embalses, instalación de una fábrica contaminante, deforestación). Puede dar lugar a reuniones ligadas a proyectos públicos y también a consejos periódicos de barrio y de ciudad. Finalmente, puede adoptar la forma 
de jurados de ciudadanos que escuchen las opiniones de politicos y expertos sobre proyectos que revistan un interés (o un peligro) pública. La democracia participativa permitiría discutir, a nivel local, problemas de interés nacional e incluso planetario...» (MORIN, 2011, p. 63-64).

Y todo esto, claro está, teniendo en cuenta y eliminando los obstáculos y dificultades que representan la globalización económica, la política y la ideológica que son las que con el sostén del paradigma mecanicista, productivista, mercantilista y neoliberal han legitimado y lo continúan haciendo, el actual desorden social establecido de desigualdad. Esta es la razón por la que entendemos que el primer factor del que hay que partir para concretar las dimensiones políticas de la contextualización educativa es el hecho de que asistimos y estamos inmersos en una crisis mundial de desigualdad e injusticia social de proporciones descomunales.

Es obvio que las desigualdades en la distribución de la riqueza están siempre en la base de todas las desigualdades sociales, por eso no podemos olvidar que estas desigualdades son las producen, inducen y reproducen todo tipo de desigualdades educativas, sanitarias, de género, de etnia y de los más diversos tipos. Si bien todas las desigualdades están vinculadas y complejamente relacionadas y ligadas al modo de producción económico, específicamente las desigualdades educativas tienen un efecto devastador en el sostenimiento y reproducción de estas desigualdades en una doble perspectiva: primera, disminuyendo las oportunidades de mejora de las condiciones materiales de existencia y segunda aun existiendo escuelas para todos, estas por diversos tipos de mecanismos, contribuyen también por desgracia, a la reproducción de las desigualdades.

\section{Complejidad y transdisciplinariedad}

Hasta aquí, hemos tratado de mostrar que contextualizar y complejizar son epistemológicamente lo mismo. No podremos jamás llegar a comprender los elementos, variables y relaciones existentes en los contextos educativos si no somos capaces de entender la complejidad de los procesos sociales, naturales y de la propia 
condición humana. Contextualizar, educativa y pedagógicamente hablando, significa en definitiva comprender que para fundamentar, desarrollar, organizar y hacer realidad cualquier proceso educativo es indispensable conocer y comprender la complejidad de esos procesos de transformación singular que subyacen, tanto en la creación y producción de conocimiento, como en los procesos madurativos y de desarrollo personal y social. En suma, sin entender el significado de la complejidad y sus expresiones y manifestaciones en los procesos educativos, no podremos contextualizar. A lo sumo, podremos adaptarnos pasivamente a las condiciones dadas, pero para iniciar procesos de cambio y transformación ya sean formativos, educativos, culturales, sociales o políticos, necesariamente tendremos que partir de visiones ecosistémicas y complejas.

Cuando hablamos de que un proceso, un proyecto, una investigación, un fenómeno, un problema o una política, es de naturaleza compleja, estamos, en realidad, afirmando que, entre otros, los siguientes aspectos:

Primero, que tal proceso, o fenómeno, está configurado e articulado en red, tejido en conjunto, o sea, está, estructural e organizacionalmente, constituido por numerosos elementos, variables, relaciones y subprocesos integrados, que se interrelacionan, de manera singular e única. Presenta, así, una dinámica operacional de naturaleza compleja, por tanto, no linear, indeterminada, sujeta al imprevisto, al inesperado e al aleatorio, sujeta a las bifurcaciones inesperadas, dependiendo de las circunstancias operacionales do sistema e del medio en lo cual está inserido. Así, al hablar de complejidad, estamos, primeramente, reconociendo su naturaleza organizacional estructurada en forma de red y que nos revela que ningún sistema opera separado de aquello que lo circunda. Según Edgar Morin, lo que nos circunda está inscrito en nosotros.

Esto genera un segundo aspecto que nos informa que cada fenómeno, evento, proyecto o realización siempre está inscrito en un contexto concreto de circunstancias, variables, unas dependientes y otras independientes o aleatorias. Es el contexto que propor- 
ciona el intercambio de energía, materia o información para que el proceso, o el proyecto, crezca y se desarrolle o, por el contrario, languidezca y muera. Para la complejidad, los hechos nunca son independientes de los contextos y no pueden aislarse de las circunstancias reales en las que son producidos. Circunstancias, éstas, que, como todos saben, se inscriben, por su vez, en determinados ámbitos o subsistemas, sean económicos, políticos, culturales, personales relacionados con las visiones, motivaciones, decisiones y conductas individuales. Por eso, para la complejidad, lo verdaderamente importante es contextualizar los eventos, hechos, procesos y fenómenos siempre que sea necesario e investigar aquellas circunstancias y relaciones de subordinación, independencia e interdependencia que hacen posible la existencia y el desarrollo de determinado fenómeno, abarcando tantas variables como sea posible. ¡Sin un contexto, las cosas no tienen sentido!

En tercer lugar, cuando utilizamos el término complejidad, también estamos diciendo que, tanto en los hechos sociales, como en los hechos naturales, individuales o personales, hay múltiples relaciones, enlaces, conexiones, interacciones y emergencias, frutos de la trama existente de naturaleza compleja, interdependiente, continua y discontinua, alimentada por los diferentes flujos que se producen en el medio ambiente. Así que no existe el ser en el vacío. Por el contrario, forma parte de una trama ecosistémica en un proceso permanente de interacción, alimentado por las relaciones constitutivas del triángulo de la vida formado por el anillo individuo, sociedad y naturaleza. Este anillo también está configurado de manera ecosistémica, a partir de una ecología individual, una ecología natural o ambiental y una ecología social y cultural. En consecuencia, cuando estamos utilizando el término complejidad, también estamos afirmando que todos los fenómenos son multirrelacionales, multidimensionales y multirreferenciales y por tanto, frutos entrelazados a partir de una dinámica organizacional de naturaleza compleja. Y esto es algo que se percibe claramente en nosotros mismos, los seres humanos. Las personas no existen en 
el vacío, ni somos seres abstractos, sino seres vivos concretos que están interactuando e intercambiando permanentemente la materia, la energía y la información con el entorno natural y social, algo que ocurre a través de diversos y variados tipos de intercambios. Y en estos intercambios, hay un ámbito de la acción humana que es cultural y una base que trae consigo valores éticos que los fundamentan, los involucran e inspiran. Lo mismo sucede en relación con los mecanismos y procedimientos que los seres humanos utilizan para construir conocimiento.

Otro aspecto para tener en cuenta en este trabajo y no menos importante que los anteriores es el reconocimiento de la naturaleza lógica de la complejidad, porque la dinámica operativa de los sistemas complejos obedece a principios que no son exclusivamente los de la lógica aristotélica tradicional al afirmar que «a todo efecto corresponde, linealmente, a una causa». Por el contrario, ellos obedecen a otros tipos de lógicas operativas que se expresan a través de procesos recursivos y retroactivos, autoecoorganizadores, hologramáticos, dialógicos, enactivos, intersubjetivos, conocidos como operadores cognitivos de la complejidad, en la que no nos detendremos ahora. La lógica de la complejidad requiere así, de nuevos instrumentos para aprender a pensar, conocer y entender lo que es complejo. Requiere nuevos instrumentos, los mecanismos cognitivos, una nueva epistemología, la epistemología de la complejidad, para el desarrollo del pensamiento, para la construcción del conocimiento y una mejor comprensión de la dinámica de la vida. Esta epistemología es contraria a la fragmentación de la realidad, del ser humano, a la fragmentación teórica y disciplinaria del conocimiento, lo que implica la superación de dualidades, tales como: sujeto/objeto; individuo/contexto, unidad/diversidad; enseñanza/aprendizaje, cuerpo/ mente, entre otras numerosas dualidades, lo que es fundamental en el estudio, en la comprensión y el establecimiento de las diferentes dimensiones de la contextualización.

Por último, hay que reconocer que aunque tengamos muy bien analizadas y estructuradas las diferentes dimensiones del con- 
texto, no debemos olvidar que la observación, el análisis y el tener en cuenta las características y dinámicas estructurales del mismo son siempre llevadas a cabo y desarrolladas a través de la acción de un ser humano único y singular, capaz de crear símbolos, producir conocimiento, transformar la realidad, al mismo tiempo, que él se transforma, se autoorganiza, siendo, al mismo tiempo, sujeto observador y objeto observado. Un ser humano de condición antropobiocósmica, de naturaleza psicosocial, biográfica e histórica, de carácter sensible, emocional y espiritual. En resumen, un ser humano es el resultado de una condición misteriosa y milagrosa, cuya naturaleza es, a su vez, errática, contradictoria y egoísta, sapiens-demens, es decir, un ser de naturaleza extraordinariamente compleja.

Así, pues, si ignoramos estos cinco elementos constitutivos y explicativos de la complejidad será imposible llevar a cabo una contextualización adecuada y eficiente que aporte pistas y perspectivas a los procesos de desarrollo social y personal, así como procesos de aprendizaje. Dice Edgar Morin que «...La globalización no sólo provoca su propia crisis. Su dinamismo acarrea crisis múltiples y variadas a escala planetaria. La crisis de la economía mundial aparecida en 2008 (...) la crisis ecológica (...) la crisis de las sociedades tradicionales (...) la crisis demográfica (...) la crisis urbana (...) la crisis del mundo rural (...) la crisis politica (...) la crisis del desarrollo (...) la crisis de la bumanidad que no logra acceder a la bumanidad...» (MORIN, 2011, p. 22). Por tanto, la primera evidencia de la que es indispensable partir para situarnos en el contexto mundial y nacional es que estamos inmersos en una crisis civilizatoria de magnitud e inconmensurables dimensiones. En realidad, lo que vivimos no es una crisis, sino una policrisis en la que diferentes crisis retroceden y se agudizan mutuamente. Las consecuencias de esta realidad son obvias: cualquier problema o dificultad que tengamos ya no es posible resolverla con recetas o reformas aisladas, sectoriales o especializadas, ya que todos los problemas están complejamente vinculados y son interdependientes, por lo que ya podemos, en principio, escribir una primera observación: contextualizar educativa y pedagógicamente significa que todo lo que sucede 
en nuestras instituciones formativas, en nuestras aulas, así como en nuestra vida profesional, laboral y personal, está de una u otra manera conectado, interrelacionado con la crisis actual del paradigma civilizatorio dominante. De aquí se deduce, por ejemplo, que tanto la visión y la misión de los sistemas educativos y de las políticas educativas, tengan necesariamente que orientarse teleológica y funcionalmente, a dar respuesta a dicha crisis con el fin de abrir nuevos caminos de transformación social y personal más coherentes con el sostenimiento y el desarrollo de la vida en nuestro planeta. ${ }^{3}$

A partir de estas consideraciones, tenemos que asumir que, al hablar de transdisciplinariedad, sea cual sea el campo, estamos, en realidad, afirmando que todos los fenómenos, procesos y proyectos en los que intervenimos son de carácter complejo y no se pueden resolver con lógicas reduccionistas, simplificadoras, especializadas y burocratizadas. Se deben buscar nuevas formas de afrontamiento que vayan mucho más allá de las disciplinas o del encarcelamiento del conocimiento en islotes o jaulas desconectadas de la realidad. La palabra transdisciplinariedad ya revela su propia naturaleza trayendo consigo el prefijo 'trans', que significa ir más allá de las disciplinas y las "jaulas epistemológicas" que nos aprisionan. Es lo que trasciende el disciplinar y, según el físico Basarab Nicolescu, está entre, a través y más allá de las disciplinas, reconociendo el dinamismo implícito de lo que sucede a otro nivel fenomenológico, en otro dominio lingüístico, es decir, en otro nivel de realidad o materialidad del objeto.

Pero ¿qué hay más allá de las disciplinas? Más allá de las disciplinas, de los objetos del conocimiento, está el SUJETO, el ser humano, con toda su multidimensionalidad, entrelazado en una realidad compleja y, por lo tanto, constituida por diferentes niveles de materialidad. Es el sujeto multidimensional, con su pensamiento racional, empírico y mágico, con su imaginario, con sus emociones, sentimientos y afectos, con su pensamiento alimentado por la intui-

3 Un resumido y detallado análisis de lo que denominamos "Crisis del estar" se encuentra en BATALLOSO (2014)

< https://www.academia.edu/24630442/La_crisis_del_estar > 
ción y la espiritualidad. Un sujeto que explora el conocimiento en sus niveles más diferentes, utilizando diferentes niveles de percepción disponibles para el ser humano, sabiendo, de antemano, que la racionalidad no se da cuenta de conocer lo real, pues, también es necesario la creatividad, la imaginación, el imaginario, la intuición y espiritualidad en búsqueda de un conocer más profundo y global.

Así, la transdisciplinariedad, además de trabajar las interacciones disciplinarias, las interrelaciones entre las diferentes áreas del conocimiento, reintroduce y reafirma una epistemología del sujeto, que rescata la subjetividad humana que se proyecta más allá de las áreas de la conocimiento, trayendo consigo las dimensiones intrasubjetivas e intersubjetivas que dialogan entre sí, revelando así las dimensiones internas y externas intrínsecas al conocimiento humano y revelando la existencia de otros niveles fenomenológicos, o niveles de realidad, que caracterizan la dinámica universal.

En consecuencia, el conocimiento transdisciplinario es lo que impregna estos niveles fenomenológicos constituyentes de la realidad, lo que surge del diálogo que el sujeto realiza con las diferentes disciplinas u objetos de conocimiento, con diferentes culturas o incluso con las múltiples dimensiones del mismo objeto. Es el conocimiento que permite el paso de un nivel de conocimiento a otro, a través de la acción conjunta de los diferentes niveles de percepción por parte de quien conoce. Cada uno percibe la realidad, o realidades, de acuerdo con su nivel de percepción y conciencia, indicando que para cada nivel de realidad corresponde a un nivel de percepción por parte del sujeto, según Nicolescu.

De una manera muy breve, sólo para ampliar nuestra capacidad de entender diferentes dimensiones de la contextualización educativa y pedagógica, objeto de nuestro trabajo, nos acercamos a Nicolescu reconociendo los tres ejes estructuradores del concepto de transdisciplinariedad: niveles de realidad, complejidad y tercero incluido. Articulando estos tres ejes, podemos decir que la realidad consiste en diferentes niveles de materialidad, con sus respectivas leyes y dominios de existencia, y uno no es más importante que 
el otro. Existe un nivel de realidad porque todos existen al mismo tiempo. Uno es lo que es porque todos los demás niveles de realidad, concomitantemente, también lo son. Las leyes que rigen un nivel de realidad son sólo parte de una totalidad de leyes que rigen todos los demás niveles constitutivos del universo, lo que revela la complejidad organizativa estructurante que conecta y reconecta todos los niveles. Por lo tanto, entendemos que la complejidad es la base estructurante del principio de la interdependencia universal que rige la dinámica misma de la vida.

Esta complejidad estructurante y de religación de los diferentes niveles de realidad, o niveles fenomenológicos, revela que no hay separatividad, sino patrones de interconexiones que constituyen una totalidad indivisible dependiendo de la energía, la materia o la información entre y en los diferentes subsistemas, provocadora de una causalidad global que afecta al sistema en su conjunto. Por lo tanto, ¿cómo entender y dialogar con esta compleja realidad mutante, que constituida de los múltiples niveles de materialidad? ¿Qué tipo de lógica se necesita? ¿La lógica binaria clásica que privilegie la dualidad, la separatividad o el tercero excluido?

Nicolescu nos informa que la lógica binaria, aristotélica, no comprende, ni representa, la totalidad del conocimiento, que se expresa a partir de la articulación simultánea de lo que sucede a los diferentes niveles de realidad. Es necesario abandonar este tipo de representación lógica que trae consigo separaciones, fragmentaciones y los más variados preconceptos que nos habitan, y que no nos ayudan a percibir, o entender, la complejidad de los fenómenos que integran la dinámica de la vida, y que también están presentes en los procesos de construcción del conocimiento y en el aprendizaje.

Por lo tanto, es necesario trabajar con la lógica del tercero incluido, revelando la existencia de una tercera posibilidad de representación diferente de la anterior, considerada un tercero dinamismo energético o informativo que se presenta en otro nivel de realidad, de materialidad o comprensión, producto de una dinámica que ocurre entre A y no A, elementos aparentemente contradic- 
torios y que, en realidad, también pueden ser complementarios al presentarse, o materializarse, a otro nivel distinto, como es el caso de la onda y la partícula que se materializan como fotón de luz. Así, lo que era inexistente y contradictorio, pasó a ser complementario reconociendo la existencia de una coherencia lógica entre dos posibilidades de representación integradora de ambas.

La lógica del tercero incluido, que une lo que sucede simultáneamente en el sujeto transdisciplinario y en los niveles de la realidad constituyentes del objeto transdisciplinario, nos lleva a pensar en una estructura abierta de conocimiento, a darnos cuenta de que siempre hay, o habrá un tercer dinamismo implícito, mismo que él no se presenta al principio. Así, la transdisciplinariedad permite la exploración de lo que circula en los diferentes niveles de materialidad del objeto, es decir, entre los diferentes niveles fenomenológicos. En otros casos, también lo que circula entre las diferentes áreas del conocimiento, entre las diferentes culturas, entre la ciencia y la tradición, así como entre los diferentes dominios lingüísticos. Es la lógica ternaria la que trabaja el paso del conocimiento de un nivel de realidad a otro.

La transdisciplinariedad, o conocimiento transdisciplinario que emana de ella, es el resultado, por lo tanto, de una complejidad estructural que une y articula lo que sucede en diferentes niveles de la realidad, por ejemplo, en diferentes disciplinas o áreas del conocimiento, y lo que sucede en los niveles de percepción y conciencia del sujeto. Es el producto de una tesitura compleja, dialógica, emergente y autoorganizada, tejida en intersticios, en las tramas de la intersubjetividad, en los meandros de la pluralidad de percepciones y significados emergentes, en función de una dinámica presente en los fenómenos eventos y procesos. La transdisciplinariedad nos ayuda a contextualizar y a ecologizar el conocimiento, así como las prácticas sociales, profesionales y culturales que apuntan a nuevas soluciones. Y esta búsqueda de nuevas soluciones implica, en parte, conocer la complejidad, en otra identificar los diferentes niveles de realidad, percepción e intervención existentes y presentes en cada 
fenómeno o en todo el proceso de intercambio energético, material e Informacional. Al mismo tiempo, en el que nos anima a caminar y asumir una lógica más integradora e inclusiva, como la lógica del tercero incluido, por la que los fenómenos aparentemente contradictorios e incompatibles pueden presentarse como complementarios e inclusivos.

\section{Conclusiones provisionales}

Si de entre los numerosos teóricos de la Educación del siglo $\mathrm{XX}$, hay alguno que haya sido capaz de hacer visible en la práctica concreta de las aulas que es imposible educar sin contextualizar y que el acto de educar es en realidad un acto de contextualización orientado a trascender, transformar y mejorar el contexto en que cada ser humano existe, vive y convive, ese es, sin duda, el insigne y universal educador y pedagogo Paulo Freire. Fue él, el primero que se dio cuenta, a finales de la década de los cincuenta del pasado siglo, que tanto leer como adquirir conocimientos no son procedimientos mecánicos de codificación simbólica o de almacenamiento de información que se guardan en depósitos para ser recordados o utilizados más tarde. No en vano, Paulo Freire, a lo largo de toda su trayectoria personal, profesional y académica nunca se cansó de repetir que la lectura de la realidad siempre precede a la lectura de la palabra, que la experiencia personal y social que cada individuo vive en su contexto concreto no solo determina y configura un singular modo de aprender y producir conocimiento, sino también una determinada actitud para interpretar, valorar y responder al contexto concreto en que ese individuo vive.

Querámoslo o no, cada ser humano en particular lleva siempre consigo un cúmulo tan variado y complejo de experiencias de relación e interacción con su contexto exterior y con su contexto interior (emociones, sentimientos, valores, motivaciones, intereses, ideales, creencias, convicciones, opiniones...), que siempre van a ser las que configuren, articulen y den sentido al original y singular proceso de maduración personal de cada uno, proceso que es siempre 
educativo, es decir, autoformativo, heteroformativo y ecoformativo. Lo queramos o no, somos seres de contexto y en contexto, por tanto, contextualizar en Educación es algo mucho más profundo, permanente y extenso, que el simple hecho de conocer determinadas características o variables que pueden obstaculizar o favorecer los procesos de enseñanza y aprendizaje. Nos educamos, no solo porque somos seres dotados de educabilidad o de capacidades para mejorar y desarrollar nuestras potenciales capacidades o talentos, sino sobre todo porque la vida humana es en realidad un proceso educativo permanente e interminable. De alguna manera y al igual que cualquier ser vivo está movido e impulsado desde su interior a vivir o a sobrevivir, los humanos estamos igualmente impulsados a aprender, a educarnos y en definitiva a vivir desplegando y actualizando todas nuestras potencialidades que son las que hacen posible los originales procesos de autorrealización. No obstante, para que ese proceso educativo vital y existencial tenga realmente sentido, es decir, sea capaz de conducirnos a mayores y mejores cotas de autorrealización, humanidad, o de sensibilidad, comprensión, justicia, fraternidad y compasión, es indispensable, no solo partir de las condiciones concretas de nuestros contextos, sino hacer visible con nuestra responsabilidad y en nuestra conducta cotidiana que ese contexto puede y debe ser transformado y mejorado.

En consecuencia, contextualizar en educación o en los procesos de enseñanza y aprendizaje, no puede ni debe ser solamente un requisito didáctico o de motivación para que nuestros alumnos se adapten o se conformen con las exigencias de lo que las burocracias escolares formalizan y decretan, o lo que el docente administra y exige explícita o implícitamente en su programa, sino que, por el contrario, se constituye, en realidad y en su dimensión más profunda, en un imperativo moral. Un imperativo moral y ético, que partiendo de que tanto la realidad social como la condición humana son de naturaleza compleja, debe estar fundado en el principio de que la función de todo educador o educadora que se precie no puede ser otra que la de ayudar incondicionalmente a que sus alum- 
nos lleguen a ser lo que están llamados a ser, es decir, lleguen a ser plenamente humanos. Esta es la razón por la que insigne pedagogo universal Paulo Freire, nunca se cansó de repetir que la Educación es al mismo tiempo un proceso político y pedagógico, es decir, un proceso que exige primero, un compromiso social y político con aquellos grupos humanos que viven de forma inhumana y segundo un compromiso teórico y práctico con la creación y el sostenimiento de nuevas y mejores condiciones para el desarrollo humano y la producción de conocimiento.

A partir de aquí y como decíamos al principio, contextualizar es sobre todo y ante todo un proceso continuo de diálogo con las diversas y diferentes realidades sociales, personales y profesionales, con el fin no solo de mejorar nuestro contexto exterior que es al mismo tiempo social, económico, político e ideológico, sin también nuestro contexto interior que es a la vez racional, emocional, sentimental y espiritual. Y si educar es imposible sin concebir que todo conocimiento nace, crece, se desarrolla y se reproduce en un contexto exterior e interior concreto caracterizado y atravesado por la complejidad de la sociedad, la vida y de nosotros mismos, hay que aceptar que los hechos y fenómenos educativos es necesario enmarcarlos, analizarlos, interpretarlos y producirlos desde una perspectiva transdisciplinar. Una perspectiva, que no solamente se preocupa de comprender las dinámicas epistemológicas internas y externas de la producción y reproducción de conocimiento, sino también y a nuestro juicio, de que realmente no solo es indispensable que la Educación sirva y opte por los sectores sociales más desfavorecidos y negados en su humanidad, sino que además debe procurar alimentar aquellas fuentes de energía motivacional y de sentido de nuestra humanidad, fuentes que no son otras que las que provienen del desarrollo de nuestra conciencia en todas sus dimensiones y especialmente de nuestra dimensión espiritual.

\section{Referencias}

BATALLOSO, Juan M. La crisis del estar. Camas (Sevilla).2014. Disponível em: 
< https://www.academia.edu/24630442/La_crisis_del_estar > Aceso em: 12 sep. 2018.

BATESON, Gregory. Pasos hacia una ecología de la mente. Buenos Aires: Lohlé-Lumen. 1998.

BAUMAN, Zygmunt. Los retos de la educación en la modernidad líquida. Barcelona: Gedisa. 2007.

BUBER, Martin. Yo y Tú. Madrid: Caparrós. 1993.

COLOM, Antonio J. Teoría del caos y práctica educativa. Eduga: revista galega do ensino. N 47. 2005. Disponível em: < https://dialnet.unirioja.es/descarga/ articulo/2554834.pdf > Aceso em: 14 nov. 2017.

CORTINA, Adela. 10 palabras claves en Ética. Estella: Verbo Divino. 1994.

ESTEFANÍA, Joaquín. El poder en el mundo. Barcelona: Plaza\&Janés. 2000.

FREIRE, Paulo. Pedagogía del oprimido. Madrid: Siglo XXI. 1975.

XXI. 1976.

La educación como práctica de la libertad. Madrid: Siglo

La naturaleza política de la educación: cultura, poder y liberación. Barcelona: Paidos-MEC. 1990.

A la sombra de este árbol. Esplugues de Llobregat (Barcelona):

El Roure. 1997.

FREIRE, Paulo y FAUNDEZ, Antônio. Por uma pedagogia da pergunta. Rio de Janeiro: Paz e Terra. 1985.

FROMM, Erich. Ética y Psicoanálisis. México D.F.: Fondo de Cultura Económica. 1953.

La revolución de la esperanza. México DF: Fondo de Cultura Económica. 1970.

GUATTARI, Félix. Las tres ecologías. Valencia: Pré-textos. 1978

MORAES, Maria C. Ecologia dos saberes. Complexidade, transdisciplinaridade e educação. São Paulo: Antakarana WHH-Proliber. 2008. 
MORIN, Edgar. Introducción al pensamiento complejo. Barcelona: Gedisa. 1994.

Los siete saberes necesarios para la educación del futuro. Paris: UNESCO. 1999.

Os sete saberes necessários à educação do futuro. São Paulo: Cortez. Brasília, DF: UNESCO, 2000.

El Método 6. La ética. Madrid: Cátedra. 2006.

- Introdução ao Pensamento Complexo. Porto Alegre: Editora

Sulina. 2007.

. O pensamento do sul. Rio de janeiro: SESC, 2011.

. Para una política de civilización. Barcelona: Paidós. 2009.

La vía para el futuro de la humanidad. Barcelona. Paidós. 2011

NICOLESCU, Basarab. O Manifesto da Transdisciplinaridade. São Paulo: Trion, 2001.

NICOLESCU, Basarab. Et al. Educação e transdisciplinaridade 11. Brasília: UNESCO, 2002.

REBELLATO, José L. Ética de la liberación. Montevideo: Nordan-Comunidad. 2000 . 